\title{
Dynamic Economic Dispatch Based on Simple Algorithm
}

\author{
S. GANESAN and S. SUBRAMANIAN
}

\begin{abstract}
This paper presents a simplified methodology to solve Dynamic Economic Dispatch (DED) problems. The main objective is to determine the most economic dispatch of on line generating units with the predicted load demands over a certain period of time. The DED is formulated as a second order dynamic optimization problem that takes into the consideration of the ramp rate limits of the generating units. The simplified methodology optimizes or provides the most economic schedule of generation for each interval in the scheduling time horizon hence the minimization of the total fuel cost is achieved. The feasibility of the proposed methodology is demonstrated for solving the dynamic economic dispatch problem with suitable test systems. The unit operation constraint and transmission loss are considered for the practical applications. The simulation results are compared with the recent reports in terms of solution quality. Numerical simulation results indicate an improvement in total fuel cost saving and hence the superiority of the proposed is also revealed for dynamic economic dispatch problems.
\end{abstract}

Index Terms-Dynamic economic dispatch, ramp rate limits, sequential approach, transmission loss.

\section{INTRODUCTION}

The primary objective of the economic dispatch problem is to schedule the generations of the online thermal units so as to meet the required load demand at minimum operating cost while satisfying the unit and system equality and inequality constraints. Dynamic Economic Dispatch (DED) is an extension of the economic dispatch problem and it aims to schedule the online thermal units with the predicted load demands over a scheduling period at minimum operating cost. DED problem is formulated as minimization of total fuel cost is the main objective while satisfying system constraints. The fuel cost of the thermal plant is normally expressed as a quadratic function of real power output of generating units hence DED problem has been formulated as a second order quadratic optimization problem that takes into the consideration of the ramp rate limits of the generating units [1-2].

In general, the DED problem has been solved by splitting the entire scheduling period in to small intervals. The economic schedule of thermal units for each interval is determined subject to power balance constraint of the interval

Manuscript received August, 2010.

S. Ganesan is with the Department of Electrical Engineering, Annamalai University, Annamalainagar, Tamilnadu, India. (e-mail: ganeshshriraj@gmail.com).

S. Subramanian is with the Department of Electrical Engineering, Annamalai University, Annamalainagar, Tamilnadu, India. (e-mail: dr_smani@yahoo.co.in). and unit operational constraints. The static or traditional economic dispatch has been performed in each interval of the scheduling period. A variety of optimization techniques have been used for solving static or traditional economic dispatch problems. The conventional methods include the lambda-iteration method, the base point and participation factors method, the gradient method, the Lagrangian relaxation method and dynamic programming. The methods based on artificial neural network and heuristic search techniques based solution methodologies have been applied to solve economic dispatch problems.

The methods based on artificial intelligent techniques, such as Simulated Annealing (SA), Genetic Algorithm (GA), Evolutionary Programming (EP) and Particle Swarm Optimization (PSO) have been given attention for solving dynamic economic dispatch problem because of their ability to find the solution near global optimal. Simulated Annealing is the stochastic optimization technique has been applied to find the solution of economic and dynamic economic dispatch problems [3]. The SA technique is similar to local search technique in optimization, which can guarantee only a local optimum. The appropriate setting of control parameters is also important for convergence and improper setting of control parameters may lead execution time. Artificial neural network based solution for economic dispatch problem has been reported [4]. The heuristic search technique, Genetic algorithm has been successfully applied to find the economic schedule of generation for economic dispatch problems [5- 7]. Evolutionary Programming technique is search algorithm based on the simulated evolutionary process of selection, variation and genetics. Evolutionary programming is more flexible and robust than conventional calculus method. Evolutionary programming technique and its modified versions have been successfully applied for solving economic dispatch problems [8]. Particle Swarm Optimization (PSO) is a modern heuristic search technique, has been developed through simulation of a simplified social system. PSO algorithm has been successfully applied to find the solution for traditional and dynamic economic dispatch problems [9].

The traditional or classical approaches and the methods based on operational research artificial intelligent concepts have been applied for solving the Dynamic Economic Dispatch problem. The classical methods such as Lagrangian Relaxation, Dynamic programming approach is accurate but suffers for non linear search spaces and large scale systems. A various artificial intelligence based methods have been developed in order to attain an improvement in the solution quality. The price based ramp model has been used to solve 
the dynamic economic dispatch problem [10]. The solution methodology using Hopfield network model has been suggested for solving dynamic economic dispatch problem [11-13]. Particle Swarm Optimization method has been successfully applied to solve DED problem [14]. The hybrid approaches have been developed to solve dynamic economic dispatch problem. A hybrid approach has been developed by combing Hopfield Neural Network and Quadratic Programming (HNNQP), has been applied for the solution of DED problems [15-16]. The authors suggested Hopfield Neural Network and quadratic programming for solving static or traditional economic dispatch part and dynamic part respectively. The DED problem has been solved by Brent Method (BM) and it is applied to determine the optimal lambda [17]. The solution techniques based on SA and hybrid EP-PSO-Sequential Quadratic Programming (SQP) have also been reported [18-19]. A survey of literature on the DED solution methods reveals that various numerical optimization techniques have been employed to approach the DED problem [20]. It is observed that the traditional and heuristic methods have some limitations to solve DED problems. The traditional methods suffer with large execution time and the heuristic methods are unable to find the optimal solution within the reasonable execution time due to their heuristic nature.

In this article, a direct search methodology based on Sequential Approach with Matrix Framework (SAMF) has been applied to solve dynamic economic dispatch problems. The proposed methodology has been validated with three test systems.

\section{PROBLEM FormLATION}

The DED problem is formulated as the minimization of total fuel cost of generating units for the entire scheduling period subject to variety of constraints. The DED problem formulation is as follows.

\section{A. Objective function}

The main objective of DED problem is to minimize the generation cost of ' $n$ ' online thermal units over a scheduling period ' $\mathrm{T}$ ' is given as,

$$
\min F=\sum_{t=1}^{T} \sum_{i=1}^{n} F C_{i, t}\left(P_{i, t}\right)
$$

Where, $\mathrm{FC}_{\mathrm{i}, \mathrm{t}}$ is the fuel cost of unit $\mathrm{i}$ at time interval $\mathrm{t}$ in $\$ / \mathrm{h}$ and $P_{i, t}$ is the real power output of generating unit $i$ at time period $t$ in $\mathrm{MW}$.

The fuel cost (FC) of generating unit at any time interval' $t$ ' is normally expressed as a quadratic function is as,

$$
F C=\sum_{t=1}^{T} \sum_{i=1}^{n} a_{i} P_{i, t}^{2}+b_{i} P_{i, t}+c_{i, t}
$$

Where, $a_{i}, b_{i}$ and $c_{i}$ are the cost coefficients of generating unit i.

\section{B. Constraints}

The objective function is minimized subject to variety of constraints.

\section{1) Power balance constraint}

This constraint is based on the principle of equilibrium that the total generation at any time interval ' $t$ ' should satisfy the load demand at the interval ' $t$ ' and transmission loss. This constraint is mathematically expressed as,

$$
\sum_{i=1}^{n} P_{i, t}=P_{D, t}+P_{L, t}
$$

Where, $\mathrm{P}_{\mathrm{D}, \mathrm{t}}$ and $\mathrm{P}_{\mathrm{L}, \mathrm{t}}$ are the load demand and transmission loss in $\mathrm{MW}$ at time interval ' $\mathrm{t}$ ' respectively.

The transmission loss can be expressed using through B coefficients.

$$
P_{L, t}=\sum_{i=1}^{n} \sum_{j=1}^{n} P_{i, t} B_{i j} P_{j, t}+\sum_{i=1}^{n} B_{0 i} P_{i, t}+B_{00}
$$

Where, $\mathrm{B}_{\mathrm{ij}}, \mathrm{B}_{0 \mathrm{i}}$ and $\mathrm{B}_{00}$ are the loss coefficients.

\section{2) Generator operational constraints}

The generating unit operational constraints such as minimum/maximum generation limit, ramp rate limits and prohibited operating zones are as follows.

a) Generator capacity constraint

$$
P_{i, \min } \leq P_{i} \leq P_{i, \max }
$$

Where, $\mathrm{P}_{\mathrm{i}, \min }$ and $\mathrm{P}_{\mathrm{i}, \max }$ are the minimum and maximum real power generation of unit $\mathrm{i}$ in MW.

b) Ramp rate limits

The inequality constraints due to ramp rate limits for unit generation changes are given

1) as generation increases

$$
P_{i}-P_{i}^{0} \leq U R_{i}
$$

2) as generation decreases

$$
P_{i}-P_{i}^{0} \leq D R_{i}
$$

The generator operation constraint after including ramp rate limit of generators can be described as,

$$
\max \left(P_{i, \min }, P_{i}^{0}-D R\right) \leq P_{i} \leq \min \left(P_{i, \max }, P_{i}^{0}+U R_{i}\right)
$$

where, $\mathrm{P}_{\mathrm{i}}{ }^{0}, \mathrm{DR}_{\mathrm{i}}$ and $\mathrm{UR}_{\mathrm{i}}$ are the real power output of generator $\mathrm{i}$ before dispatched hour in $\mathrm{MW}$, down ramp and up ramp limit of generator i in $\mathrm{MW} / \mathrm{h}$ respectively.

\section{Solution Methodology}

\section{A. Economic dispatch solution using SAMF}

Sequential approach with matrix framework has been developed for solving economic dispatch problems. A maiden attempt has been made to determine the optimal generation dispatches of a system for all possible load demands in single execution. The demonstration of the solution methodology is presented in this section.

The electric power production in a power plant is allowed to vary from minimum technical limit $\left(\mathrm{P}_{\min }\right)$ to maximum technical limit $\left(\mathrm{P}_{\max }\right)$. Initially the $\mathrm{P}_{\mathrm{i} \text {,min }}$ of all generating units in a power plant are considered as initial state input values and is represented by a single dimensional matrix as,

$$
s=\left[P_{1, \min } P_{2, \min } P_{3, \min }, \ldots \ldots, P_{n, \min }\right]
$$

Based on the above single dimensional matrix, a square matrix (I) is developed to identify the economic schedule of generation. The formation of the square matrix is as follows. The process starts with a step increment in generation by $\Delta$ MW in $\mathrm{P}_{1, \text { min }}$ by keeping the remaining units at its input value. 
This will form first row of the square matrix.

$$
I_{1}=\left[P_{1, \text { min }}+\Delta P_{2, \min } P_{3, \min }, \ldots \ldots, P_{n, \min }\right]
$$

The increment in generation is made in the second element by keeping the other elements at its input value that leads to the development of second row of the square matrix.

$$
I_{2}=\left[P_{1, \min } P_{2, \min }+\Delta P_{3, \min }, \ldots \ldots, P_{n, \min }\right]
$$

In the same logic, an increment is made for remaining units one at a time and a square matrix with a dimension equal to the number of units has been developed. For every step increment in the operating range of the plant the unit one at a time is allowed to experience the change in generation thus leads to the formation of the square matrix.

$$
I=\left[\begin{array}{l}
I_{1} \\
I_{2} \\
\cdot \\
I_{n}
\end{array}\right]=\left[\begin{array}{cccc}
P_{1, \min }+\Delta & P_{2, \min } & \ldots & P_{n, \min } \\
P_{1, \min } & P_{2, \min }+\Delta & \ldots & P_{n, \min } \\
\cdot & \cdot & \cdot & \cdot \\
P_{1, \min } & P_{2, \min } & \ldots & P_{n, \text { min }}+\Delta
\end{array}\right]
$$

Each element in the square matrix represents the generation of a unit corresponding to the column that should satisfy the unit capacity constraints.

In the square matrix the unit generations of each row that satisfy the constraints are identified and total fuel cost of generation is evaluated. The desired economic schedule of generation is identified by analyzing fitness of each row. The fitness function of each row is calculated as,

$$
f i t(j)=\frac{F_{T}(j)}{(p d+\Delta)} \quad j=1,2, \ldots n
$$

where, pd is the total of input values.

The schedule with the minimum fitness is chosen as the successive state input values. This process is repeated till all the generating units reach their maximum generation capacity. The feasible solutions for every increment from $\mathrm{P}_{\text {min }}$ to $\mathrm{P}_{\max }$ are obtained and hence the best solution for any load demand falls in the operating boundary can be easily sited.

The detailed computational flow of SAMF is presented in Fig. 1. The proposed methodology in the form of matrix framework to support the demonstration is as follows.

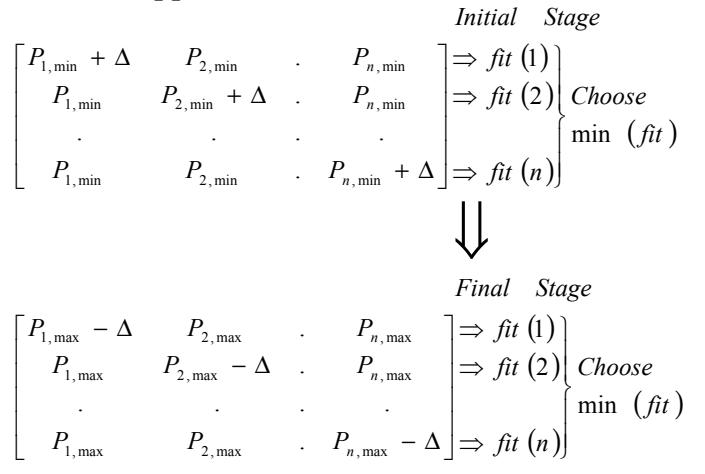

\section{IMPLEMENTATION OF THE PROPOSED METHOD}

The solution methodology for solving dynamic economic dispatch problem is presented in this section. The scheduling period is divided into a number of intervals. The optimal dispatches of online thermal units are determined for each interval hence the minimum total fuel cost for entire scheduling period is achieved.

Consider a thermal plant consist of ' $n$ ' thermal plants with a scheduling period of ' $T$ '. The entire scheduling period is divided into a number of small intervals and the load demand for each time interval is predefined. For the first interval in the scheduling period, the unit operational constraints are also enforced and SAMF is performed to obtain the optimal dispatch of generating units.

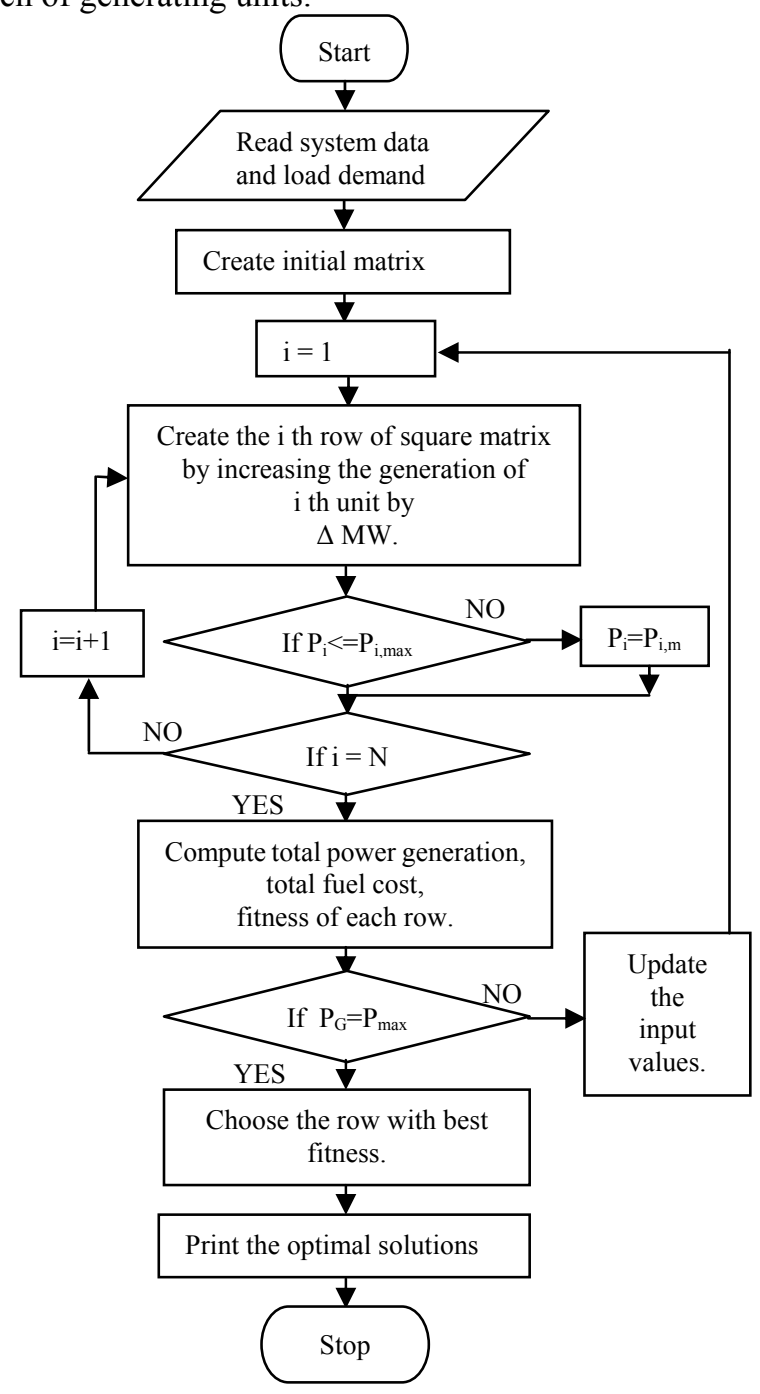

Fig. 1. Computational flow of SAMF

For second interval in the scheduling period, the real power output of the previous interval determines the minimum and maximum operating region of the generating units and considering these limits again the SAMF is performed to obtain the optimal dispatch of generating units. This process id repeated till the optimal dispatches obtained for all intervals. The computational flow of the proposed methodology is presented in Fig. 2. The algorithmic steps of the proposed methodology are as follows.

Step 1: Read system data including unit characteristics, scheduling period $(\mathrm{T})$ and load demand for each interval.

Step 2: Set interval $=1$;

Step 3: Calculate the minimum operating limit of each generating unit after enforcing the ramp rate limits.

Step 4: Perform SAMF and obtain the optimal dispatch of generating units.

Step 5: Check if interval $==T$, goto Step 7 else goto next Step. 
Step 6: Set interval $=$ interval +1 and update the minimum and maximum operating limit of each generating unit.

Step 7: Calculate the total fuel cost for the entire scheduling period.

Step 8: Print the results.

Step 9: Stop.

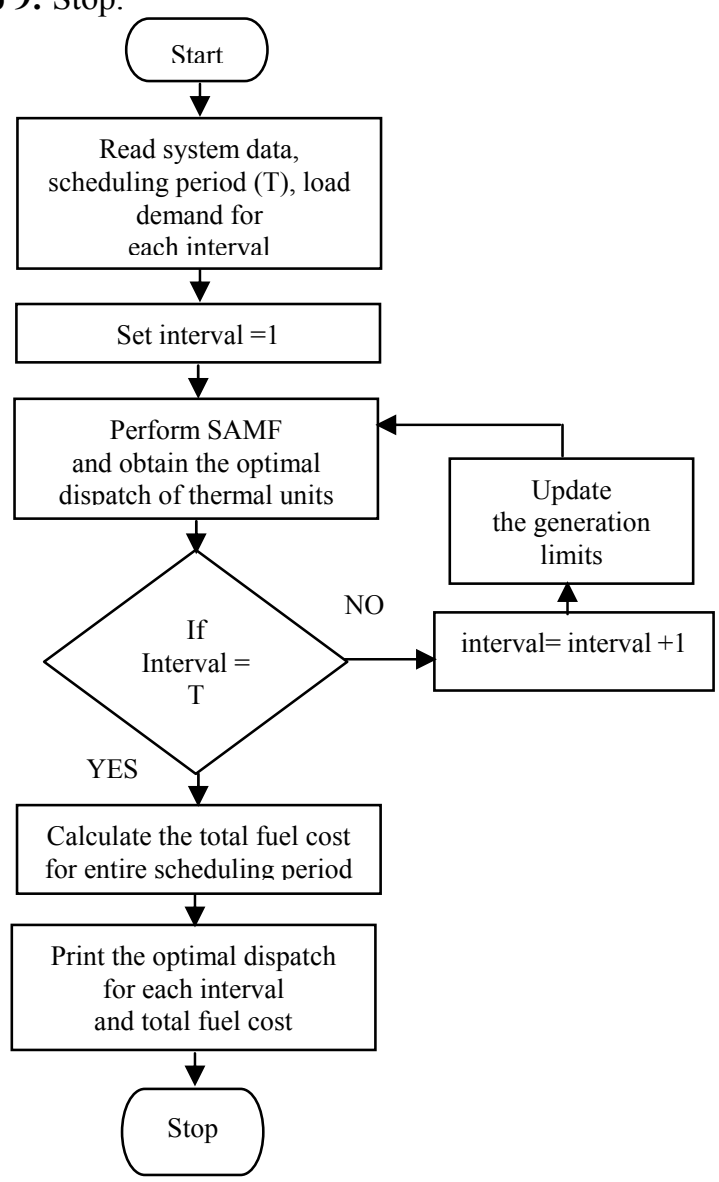

Fig. 2. Solution methodology for solving DED problem

\section{Simulation Results AND Discussions}

The proposed methodology for solving DED problem is implemented in Matlab 7.0 platform and executed with Pentium IV, 2.8 GHz personal computer. The effectiveness of the proposed methodology has been tested with three different scale of power system cases. The six unit, ten unit and fifteen unit system are considered for the analysis. The generating unit operational constraint, ramp rate limits and transmission loss are considered. The optimal dispatch of generators for each interval is obtained by SAMF. In SAMF, the selection of increment is important, too large increment may end up with unfeasible solution and too small increment may take long execution time. Based on experience, the desired increment is chosen as $1 \mathrm{MW}$.

\section{A. Case 1: 10 unit system}

The cost coefficients, maximum and minimum generation limits, ramp rate limits and load demand for each interval are presented in the literature [15]. The scheduling period of 12 intervals is considered. The minimum and maximum load demands of the scheduling period are $5540 \mathrm{MW}$ and 6041 MW. The optimal dispatches of units for each interval are obtained and the schedule of generation is presented in Table I. The solution obtained by SAMF is compared with the recent report HHNNQP and the comparison is presented in Table II. The comparison clearly indicates that the proposed methodology provides a superior schedule.

TABLE I: THE OPTIMAL DISPATCHES OF TEN UNIT SYSTEM

\begin{tabular}{|c|c|c|c|c|c|c|}
\hline $\mathrm{U} \backslash \mathrm{t}$ & 1 & 2 & 3 & 4 & 5 & 6 \\
\hline 1 & 239 & 244 & 262 & 238 & 258 & 278 \\
\hline 2 & 355 & 361 & 381 & 356 & 376 & 396 \\
\hline 3 & 411 & 417 & 439 & 411 & 461 & 474 \\
\hline 4 & 475 & 482 & 505 & 475 & 525 & 543 \\
\hline 5 & 416 & 421 & 442 & 416 & 466 & 476 \\
\hline 6 & 547 & 556 & 589 & 547 & 597 & 641 \\
\hline 7 & 620 & 620 & 620 & 620 & 620 & 620 \\
\hline 8 & 643 & 643 & 643 & 643 & 643 & 643 \\
\hline 9 & 908 & 919 & 920 & 908 & 920 & 920 \\
\hline 10 & 946 & 957 & 999 & 946 & 1046 & 1050 \\
\hline $\mathrm{P}_{\mathrm{D}}$ & 5560 & 5620 & 5800 & 5560 & 5990 & 6041 \\
\hline $\mathrm{FC}$ & 173395 & 176058 & 184199 & 173395 & 189424 & 195494 \\
\hline \multicolumn{7}{|r|r|r|r|}{} \\
\hline $\mathrm{U} \backslash \mathrm{t}$ & 7 & 8 & 9 & 10 & 11 & 12 \\
\hline 1 & 282 & 261 & 249 & 237 & 251 & 257 \\
\hline 2 & 404 & 380 & 367 & 353 & 369 & 376 \\
\hline 3 & 463 & 438 & 425 & 410 & 426 & 433 \\
\hline 4 & 532 & 504 & 490 & 473 & 491 & 499 \\
\hline 5 & 466 & 441 & 428 & 414 & 429 & 436 \\
\hline 6 & 625 & 586 & 567 & 544 & 568 & 579 \\
\hline 7 & 620 & 620 & 620 & 620 & 620 & 620 \\
\hline 8 & 643 & 643 & 643 & 643 & 643 & 643 \\
\hline 9 & 920 & 920 & 920 & 904 & 920 & 920 \\
\hline 10 & 1046 & 997 & 971 & 942 & 973 & 987 \\
\hline $\mathrm{P}_{\mathrm{D}}$ & 6001 & 5790 & 5680 & 5540 & 5690 & 5750 \\
\hline $\mathrm{FC}$ & 193579 & 183741 & 178745 & 172513 & 179195 & 181913 \\
\hline
\end{tabular}

TABLE II: TOTAL COST COMPARISON OF CASE 1

\begin{tabular}{|c|c|}
\hline Method & Total cost (\$) \\
\hline HHNNQP [15] & 2196210 \\
\hline SAMF & 2181651 \\
\hline
\end{tabular}

\section{B. Case 2: Six unit system}

The system contains six thermal units and the details including cost coefficients, generation limits, ramp rate limits, transmission loss coefficients and forecasted load demand of each interval are presented in the literature [17]. The transmission loss is calculated using B coefficients. The one day scheduling period is divided into 24 intervals. The optimal dispatch of generating units is determined by SAMF. The minimum and maximum operating limit of each generating unit is obtained by enforcing the ramp down and ramp up limits of generating unit with the real power dispatch of previous interval. The minimum and maximum load demand in the scheduling period is $930 \mathrm{MW}$ and $1263 \mathrm{MW}$ respectively. The optimal dispatches of the entire scheduling period are presented in Table III. The solution obtained by SAMF method and Brent method are compared. The comparison is presented in Table IV. From the comparison, it is clear that the proposed methodology provides an improvement in the total cost savings.

\section{Case 3: 15 unit system}

The cost coefficients, maximum and minimum generation limits, load demand for each interval and the transmission loss coefficients are presented in the literature [17]. The transmission loss is calculated using transmission loss coefficients. The one day scheduling period is considered and the scheduling period is divided into 24 equal intervals. The minimum and maximum load demands of the scheduling 
period are 2226 and $2970 \mathrm{Mw}$. The optimal dispatches of units for each interval are obtained and the schedule of generation is presented in Table $\mathrm{V}$. The solution obtained by SAMF and BM are compared and the comparison is presented in Table VI. The comparison clearly indicates that the proposed methodology provides a better schedule than recent reports.

The total execution time of the different methods for the solution of DED problems are presented in Table VII. The execution times shown may not be directly comparable due to different configuration of computer hardware and programming languages used but some insight can be gained.
This comparison indicates that the proposed takes less execution time than other heuristic search methods.

The proposed methodology has following merits.

- From these studies, this approach has the competence to solve dynamic economic dispatch problem.

- In all cases, the proposed methodology provides the best schedule of generation with minimum total fuel cost hence the global optimal solution.

- The performance of the proposed approach is independent of the number of generating units in the system and hence it is suitable for system of any size.

- The computational procedure is minimal.

TABLE III:THE OPTIMAL DisPATCHES OF SIX UNIT SySTEM

\begin{tabular}{|c|c|c|c|c|c|c|c|c|c|}
\hline$t \backslash U$ & 1 & 2 & 3 & 4 & 5 & 6 & $P_{D}$ & $P_{L}$ & $\begin{array}{l}\text { Fuel Cost } \\
\text { (\$) }\end{array}$ \\
\hline $\mathrm{P}_{i}^{0}$ & 340 & 134 & 240 & 90 & 110 & 52 & --- & --- & --- \\
\hline 1 & 380.3484 & 124 & 211 & 84 & 113 & 50 & 955 & 7.3484 & 11420.26 \\
\hline 2 & 377 & 121 & 209.1497 & 82 & 110 & 50 & 942 & 7.1497 & 11257.52 \\
\hline 3 & 375 & 120 & 208.0632 & 80 & 109 & 50 & 935 & 7.0632 & 11170.22 \\
\hline 4 & 374 & 119 & 206.9952 & 79 & 108 & 50 & 930 & 6.9952 & 11107.97 \\
\hline 5 & 375 & 120 & 208.0632 & 80 & 109 & 50 & 935 & 7.0632 & 11170.22 \\
\hline 6 & 382 & 125 & 213.4453 & 86 & 114 & 50 & 963 & 7.4453 & 11520.50 \\
\hline 7 & 389 & 130 & 217.8196 & 91 & 119 & 50 & 989 & 7.8196 & 11848.34 \\
\hline 8 & 397 & 136 & 224.3228 & 98 & 126 & 50 & 1023 & 8.3228 & 12280.80 \\
\hline 9 & 419 & 152 & 241.8625 & 116 & 143 & 64 & 1126 & 9.8625 & 13614.64 \\
\hline 10 & 424 & 156 & 245.2431 & 120 & 147 & 68 & 1150 & 10.2431 & 13930.14 \\
\hline 11 & 434 & 164 & 254.0921 & 128 & 155 & 77 & 1201 & 11.0921 & 14606.48 \\
\hline 12 & 441 & 169 & 256.6832 & 134 & 161 & 82 & 1235 & 11.6832 & 15061.82 \\
\hline 13 & 432 & 162 & 251.9155 & 126 & 154 & 75 & 1190 & 10.9155 & 14459.92 \\
\hline 14 & 445 & 171 & 261.9562 & 137 & 163 & 85 & 1251 & 11.9562 & 15277.34 \\
\hline 15 & 447 & 173 & 264.1730 & 139 & 165 & 87 & 1263 & 12.1730 & 15439.50 \\
\hline 16 & 445 & 171 & 261.9535 & 136 & 163 & 85 & 1250 & 11.9535 & 15263.85 \\
\hline 17 & 439 & 167 & 257.4419 & 131 & 158 & 80 & 1221 & 11.4419 & 14873.90 \\
\hline 18 & 435 & 164 & 254.1117 & 128 & 155 & 77 & 1202 & 11.1117 & 14619.82 \\
\hline 19 & 426 & 157 & 247.3925 & 121 & 148 & 70 & 1159 & 10.3925 & 14048.91 \\
\hline 20 & 412 & 147 & 236.3508 & 110 & 138 & 58 & 1092 & 9.3508 & 13170.71 \\
\hline 21 & 397 & 136 & 224.3228 & 98 & 126 & 50 & 1023 & 8.3228 & 12280.80 \\
\hline 22 & 388 & 129 & 216.747 & 90 & 118 & 50 & 984 & 7.7470 & 11785.10 \\
\hline 23 & 385 & 127 & 215.6239 & 88 & 117 & 50 & 975 & 7.6239 & 11671.50 \\
\hline 24 & 381 & 125 & 212.4087 & 85 & 114 & 50 & 960 & 7.4087 & 11482.84 \\
\hline \multicolumn{9}{|c|}{ Total cost (\$) } & 313363.12 \\
\hline
\end{tabular}

TABLE IV:TOTAL COST COMPARISON OF CASE 2

\begin{tabular}{|c|c|}
\hline Method & Total cost (\$) \\
\hline$\lambda-$ iteration [17] & 313405.65 \\
\hline BM [17] & 313405.40 \\
\hline SAMF & 313363.12 \\
\hline
\end{tabular}

TABle V:THE Optimal Dispatches OF FifTEEN Unit System

\begin{tabular}{|c|c|c|c|c|c|c|c|c|c|c|c|c|}
\hline$t \backslash U$ & 1 & 2 & 3 & 4 & 5 & 6 & 7 & 8 & 9 & 10 & 11 & 12 \\
\hline 1 & 299.4497 & 379 & 379 & 380 & 398 & 404 & 411 & 452 & 455 & 455 & 455 & 455 \\
\hline 2 & 330 & 356.3711 & 295.4111 & 297.4924 & 323.4391 & 333.7384 & 344.0506 & 406.1324 & 455 & 455 & 455 & 455 \\
\hline 3 & 130 & 130 & 130 & 130 & 130 & 130 & 130 & 130 & 130 & 130 & 130 & 130 \\
\hline 4 & 130 & 130 & 130 & 130 & 130 & 130 & 130 & 130 & 130 & 130 & 130 & 130 \\
\hline 5 & 306 & 186 & 150 & 150 & 150 & 150 & 150 & 150 & 229.7866 & 309.0364 & 353.307 & 356.4864 \\
\hline 6 & 283 & 363 & 443 & 445 & 460 & 460 & 460 & 4604 & 460 & 460 & 460 & 460 \\
\hline 7 & 367 & 447 & 465 & 465 & 465 & 465 & 465 & 465 & 465 & 465 & 465 & 465 \\
\hline 8 & 163 & 63 & 60 & 60 & 60 & 60 & 60 & 60 & 60 & 60 & 60 & 60 \\
\hline 9 & 25 & 25 & 25 & 25 & 25 & 25 & 25 & 25 & 25 & 25 & 25 & 25 \\
\hline 10 & 34 & 25 & 25 & 25 & 25 & 25 & 25 & 25 & 31 & 51 & 63 & 64 \\
\hline 11 & 56 & 40 & 34 & 34 & 37 & 38 & 38 & 44 & 77 & 80 & 80 & 80 \\
\hline 12 & 80 & 55 & 51 & 51 & 53 & 54 & 54 & 59 & 80 & 80 & 80 & 80 \\
\hline 13 & 27 & 30 & 27 & 32 & 31 & 31 & 29 & 29 & 28 & 27 & 27 & 26 \\
\hline 14 & 16 & 15 & 15 & 15 & 15 & 15 & 15 & 15 & 15 & 15 & 16 & 15 \\
\hline 15 & 15 & 15 & 15 & 15 & 15 & 15 & 15 & 15 & 15 & 15 & 15 & 15 \\
\hline$P_{D}$ & 2236 & 2240 & 2226 & 2236 & 2298 & 2316 & 2331 & 2443 & 2630 & 2728 & 2783 & 2785 \\
\hline $\mathrm{P}_{\mathrm{L}}$ & 25.4497 & 19.3711 & 18.4111 & 18.4924 & 19.4391 & 19.7384 & 20.0506 & 22.1324 & 25.7866 & 29.0364 & 31.3070 & 31.4864 \\
\hline $\begin{array}{l}\text { Fue } \\
1 \\
\text { cost } \\
(\$) \\
\end{array}$ & 28597.94 & 28428.80 & 28254.82 & 28372.95 & 29021.31 & 29210.60 & 29363.23 & 30545.24 & 32544.89 & 33612.99 & 34221.62 & 34240.72 \\
\hline$t \backslash U$ & 13 & 14 & 15 & 16 & 17 & 18 & 19 & 20 & 21 & 22 & 23 & 24 \\
\hline
\end{tabular}




\begin{tabular}{|c|c|c|c|c|c|c|c|c|c|c|c|c|}
\hline 1 & 455 & 455 & 455 & 455 & 455 & 455 & 455 & 455 & 449 & 405 & 387 & 385 \\
\hline 2 & 455 & 455 & 455 & 455 & 455 & 455 & 454.9164 & 155 & 400.9532 & 333.7478 & 307.893 & 303.7556 \\
\hline 3 & 130 & 130 & 130 & 130 & 130 & 130 & 130 & 130 & 130 & 130 & 130 & 130 \\
\hline 4 & 130 & 130 & 130 & 130 & 130 & 130 & 130 & 130 & 130 & 130 & 130 & 130 \\
\hline 5 & 352.2556 & 387.3713 & 447 & 469.6199 & 437.7371 & 363.9267 & 252 & 207.8932 & 150 & 150 & 150 & 150 \\
\hline 6 & 460 & 460 & 460 & 460 & 460 & 460 & 460 & 460 & 460 & 460 & 454 & 451 \\
\hline 7 & 465 & 465 & 465 & 465 & 465 & 465 & 465 & 465 & 465 & 465 & 465 & 465 \\
\hline 8 & 60 & 60 & 100.5715 & 60 & 60 & 60 & 60 & 60 & 60 & 60 & 60 & 60 \\
\hline 9 & 25 & 25 & 25 & 25 & 25 & 25 & 25 & 25 & 25 & 25 & 25 & 25 \\
\hline 10 & 63 & 76 & 111 & 118 & 93 & 67 & 34 & 25 & 25 & 25 & 25 & 25 \\
\hline 11 & 80 & 80 & 80 & 80 & 80 & 80 & 77 & 64 & 44 & 38 & 35 & 35 \\
\hline 12 & 80 & 80 & 80 & 80 & 80 & 80 & 80 & 75 & 58 & 54 & 52 & 52 \\
\hline 13 & 26 & 28 & 29 & 28 & 29 & 27 & 25 & 27 & 27 & 26 & 29 & 31 \\
\hline 14 & 15 & 17 & 27 & 19 & 24 & 22 & 15 & 15 & 15 & 15 & 15 & 15 \\
\hline 15 & 15 & 15 & 15 & 15 & 15 & 15 & 15 & 15 & 15 & 15 & 15 & 15 \\
\hline$P_{D}$ & 2780 & 2830 & 2970 & 2950 & 2902 & 2803 & 2651 & 2584 & 2432 & 2312 & 2261 & 2254 \\
\hline $\mathrm{P}_{\mathrm{L}}$ & 31.2556 & 33.3713 & 40.7215 & 39.6199 & 36.7371 & 31.9267 & 26.9164 & 24.8932 & 21.9532 & 19.7478 & 18.893 & 18.7556 \\
\hline $\begin{array}{l}\text { Fue } \\
1 \\
\text { cost } \\
(\$)\end{array}$ & 34185.25 & 34747.62 & 36363.14 & 36100.99 & 35563.14 & 34450.09 & 32770.22 & 32044.57 & 30423.76 & 29155.44 & 28627.38 & 28559.18 \\
\hline
\end{tabular}

TABLE VI: TOTAL COST COMPARISON OF CASE 3

\begin{tabular}{|c|c|}
\hline Method & Total cost (\$) \\
\hline BM [17] & 760287.232 \\
\hline SAMF & 759406.42 \\
\hline
\end{tabular}

TABLE VII:TOTAL EXECUTION TIME

\begin{tabular}{|c|c|}
\hline Test system & Execution time (s) \\
\hline 6 unit system & 1.965 \\
\hline 10 unit system & 0.624 \\
\hline 15 unit system & 2.951 \\
\hline
\end{tabular}

\section{CONCLUSION}

This article presents a simple and efficient direct search approach based on sequential approach with matrix framework for solving dynamic economic dispatch problems. The effectiveness of the proposed methodology is validated by solving the different scale of dynamic economic dispatch problems. The practical operational constraint of generators like ramp rate limits and transmission loss are included in the analysis. The proposed SAMF provides the most economical dispatches for each interval in the scheduling period hence the optimal solution for DED problem. The simulation results of different case studies are compared with the earlier reports. The comparison of results concludes that the proposed methodology provides the minimum total fuel cost hence global optimal solution for dynamic economic dispatch problems.

\section{ACKNOWLEDGMENT}

The authors gratefully acknowledge the management the support and facilities provided by the authorities of Annamalai University, Annamalainagar, India to carry out this research work.

\section{REFERENCES}

[1] X.S. Han, H. B. Gooi, and D. S. Kirschen, "Dynamic economic dispatch: Feasible and optimal solutions", IEEE Trans. Power Systems, vol. 16, no. 1, pp. 22-28, Feb. 2001.

[2] W.R. Barcelo and P. Rastgoufard, "Dynamic dispatch using the extended security constrained economic dispatch algorithm", IEEE Trans. Power Systems, vol. 12, no. 2, pp. 961-967, May 1997.
[3] K.P. Wong and C.C. Wang, "Simulated annealing based economic dispatch problem", IEE Proc. Generation, Transmission and Distribution, vol. 140, no. 6, pp. 509-515, Nov 1993.

[4] T. Yalcinoz and M.J. Short, "Neural networks approach for solving economic dispatch problem with transmission capacity constraints", IEEE Trans. Power Systems, vol. 13, no. 2, pp. 307-313, May 1998.

[5] A. Bakirtzis, V. Petridis and S. Kazarlis, "Genetic algorithm solution to the economic dispatch problem", IEE Proc. Generation, Transmission and Distribution, vol. 141, no. 4, pp. 377-382, July 1994.

[6] P.H. Chen and H.C. Chang, "Large scale economic dispatch by genetic algorithm", IEEE Trans. Power Systems, vol. 10, no. 4, pp. 1919-1926, Nov.1995.

[7] S.O. Orero and M.R. Erving, "Economic dispatch of generators with prohibited operating zones: a genetic algorithm approach", IEE Proc. Generation, Transmission and Distribution, vol. 143, pp. 529-534, 1996.

[8] N. Sinha, R. Chakrabarti and P.K. Chattopadhayay, "Evolutionary programming techniques for economic load dispatch", IEEE Trans. Evolutionary Computation, vol. 7, no. 1, pp. 83-94, Feb 2003.

[9] Z.L. Gaing, "Particle swarm optimization to solving the economic dispatch considering the generator constraints", IEEE Trans. Power Systems, vol. 18, no. 3, pp. 1187-1195, Aug 2003.

[10] F. N. Lee, L. Lemonidis and K. Liu, "Price based ramp rate model for dynamic dispatch and unit commitment", IEEE Trans. Power Systems, vol. 9, no. 3, pp. 1233-1242, Aug 1994.

[11] R.H. Liang, "A neural based redispatch approach to dynamic generation allocation", IEEE Trans. Power Systems, vol. 14, no. 4, pp. 1388-1393, Nov.1999.

[12] D.W. Ross and S. Kim, "Dynamic economic dispatch of generation", IEEE Trans. Power App. Systems, vol. PAS-99, no. 6, pp. 2060-2067, Nov/Dec 2002.

[13] A.H. Rashed, E.N. Abdallah and F. Benhamida, "A Hopfield neural network based dynamic dispatch solver", Proc. Tenth international middle east power system conference (MEPCON '05), Dec 2005, vol. 2, pp. 515-525.

[14] Z.L. Gaing, "Constrained dynamic economic dispatch solution using particle swarm optimization", IEEE Power Engineering Society General Meeting, pp.153-158, 2004.

[15] S.F. Mekhamer, A.Y. Abdelaziz, M.Z. Kamh and M.A.L. Badr, "Dynamic economic dispatch using a hybrid Hopfield neural network quadratic programming based technique", Electric Power Comp. Systems, vol. 37, pp. 253-264, 2009.

[16] A.Y. Abdelaziz, M.Z. Kamh, S.F. Mekhamer and M.A.L. Badr, "A hybrid HNN-QP approach for dynamic economic dispatch problem", Elect. Power Syst. Res., vol. 78, no. 10, pp. 1784-1788, 2008.

[17] K. Chandram, N. Subrahmanyam and M. Sydulu, "Brent method for dynamic economic dispatch with transmission losses", Iranian J. Elect. Computer Engineering, vol. 8, no. 1, pp. 16-22, Winter-Spring 2009.

[18] S. Titus and A. Ebenezer Jeyakumar, "A hybrid EP-PSO-SQP algorithm for dynamic dispatch considering prohibited operating zones", Electric Power Comp. Systems, vol. 36, pp. 449-467, 2008.

[19] C.K. Panigrahi, P.K. Chattopadhyay, R.N. Chakrabarti and M. Basu, "Simulated annealing technique for economic dispatch", Electric Power Comp. Systems, vol. 34, pp. 577-586, 2006.

[20] X. Xia and A.M. Elaiw, "Optimal dynamic economic dispatch of generation: A review”, Elect. Power Syst. Res., vol. 80, pp. 975-986, 2010. 
1793-8163

S. Ganesan is a member of Indian society of Technical Education. He is working as an Assistant Professor in the Department of Electrical Engineering, Annamalai University. He received the B.E degree in Electrical and Electronics Engineering from Government College of Engineering, Salem, India in 2002 and M.E degree in Power Systems with distinction in the year 2008 from Annamalai University, Annamalainagar, India. He is currently pursuing Ph.D degree (Part-time) in the Department of Electrical Engineering, Annamalai University, Annamalainagar, India. His research topics include power systems operation and control.

S. Subramanian is a Professor with the Department of Electrical Engineering, Annamalai University, Annamalainagar, India. He is a Senior member in IEEE, Fellow of Institution of Engineers (India) and a member of various professional bodies such as System Society of India, India Society for Technical Education and Indian Science Congress Association. He received the B.E degree in Electrical and Electronics Engineering and the M.E degree in Power Systems with distinction from Madurai Kamaraj University, Madurai, India in the year 1989 and 1990 respectively. He received the Ph.D degree in the year 2001 from Annamalai University, Annamalainagar, India. He published 115 research articles in various referred international journals, national journals, international conferences and national conferences. He is a review committee member for various international and national journals. His area of interest includes power system operation and control, design analysis of electrical machines, power system state estimation and power system voltage stability studies. His biography has been included in MARQUIS who is who in the world, MARQUIS who is who in Engineering and International Biographical Centre (IBC), UK. He received the best teacher award in recognition of his research contributions in Annamalai University. 